Document downloaded from:

http://hdl.handle.net/10251/123138

This paper must be cited as:

Ruano, MV.; Ribes, J.; Seco Torrecillas, A.; Ferrer, J. (2012). An advanced control strategy for biological nutrient removal in continuous systems based on $\mathrm{pH}$ and ORP sensors. Chemical Engineering Journal. 183:212-221. https://doi.org/10.1016/j.cej.2011.12.064

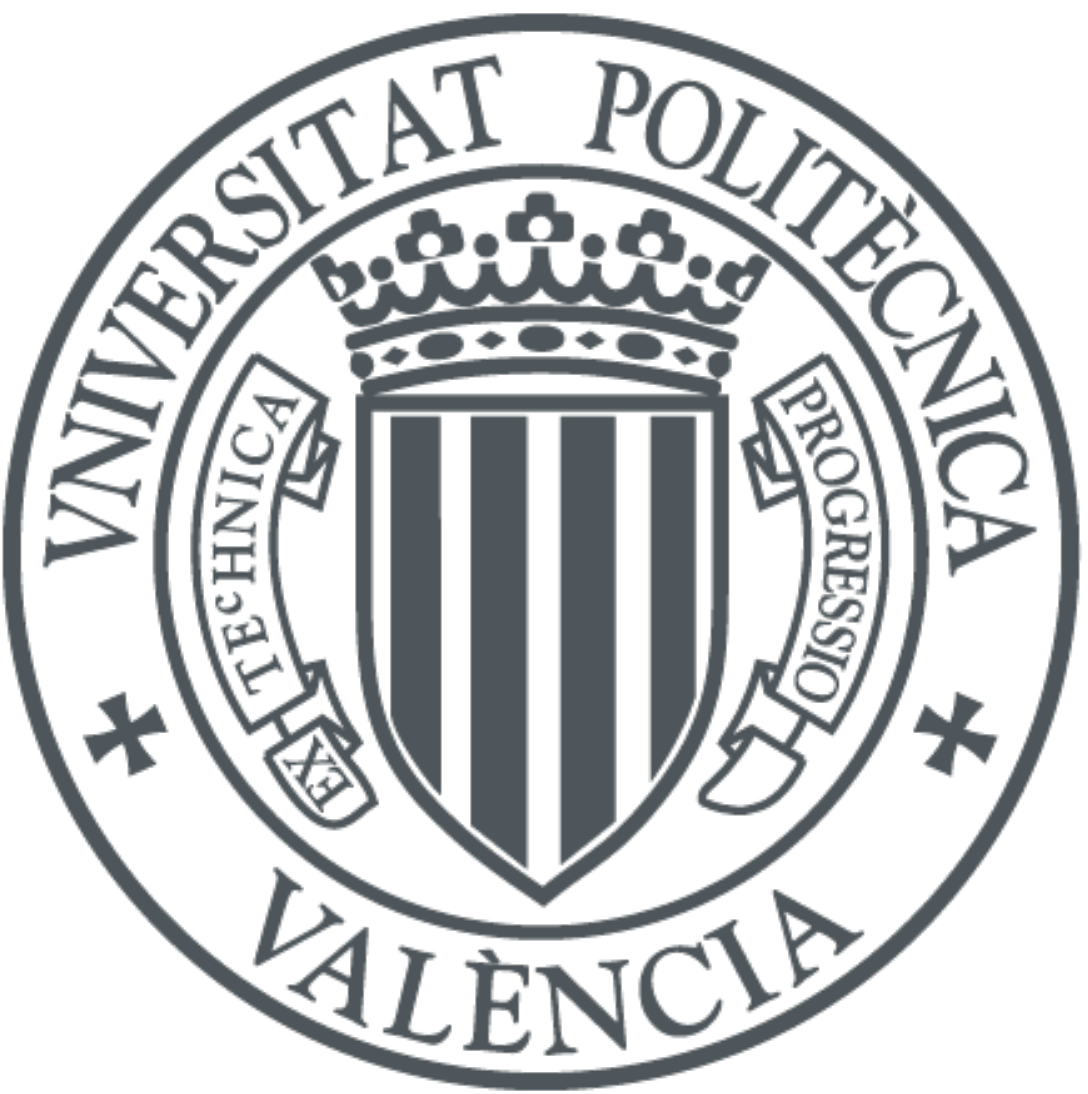

The final publication is available at

http://doi.org/10.1016/j.cej.2011.12.064

Copyright Elsevier

Additional Information 


\title{
An advanced control strategy for biological nutrient removal in continuous systems based on $\mathrm{pH}$ and ORP sensors
}

\author{
M.V. Ruano ${ }^{\mathrm{a},{ }^{*}}$, J. Ribes ${ }^{\mathrm{a}}$, A. Seco ${ }^{\mathrm{a}}$ and J. Ferrer ${ }^{\mathrm{b}}$
}

${ }^{a}$ Dep. Enginyeria Química, Universitat de València. Dr. Moliner, 50. 46100 - Burjassot. València. Spain. Tel.: +34963877007 ext 76131; Fax.: +34 963877617 (E-mail: m.victoria.ruano@uv.es; josep.ribes@uv.es; aurora.seco@uv.es)

bInstituto de Ingeniería del Agua y Medio Ambiente. Universidad Politécnica de Valencia. Camino de Vera s/n. 46022. Valencia. SPAIN. (E-mail: jferrer@hma.upv.es)

\begin{abstract}
A fuzzy logic-based control system that uses low-cost sensors for controlling and optimizing the biological nitrogen removal in continuous systems has been developed. The novelty of this control system is the use of several $\mathrm{pH}$, ORP, and dissolved oxygen (DO) sensors instead of on-line nitrogen sensors/analyzers. The nitrogen control system was developed and implemented in a UCT pilot plant fed with wastewater from a full-scale plant. The developed nitrification controller allows the effluent ammonium concentration to be maintained below the effluent criteria discharge with the minimum energy consumption. The denitrification process controller allows the energy consumption derived from pumping to be minimized, as the control system only increases the internal recycle flow rate when the anoxic reactor reveals further capacity for denitrification. This advanced control strategy offers an attractive alternative to on-line, nitrogen analyzer-based control systems since it involves lower investment, maintenance, and operational costs that are derived from the instrumentation.
\end{abstract}

Keywords

Biological Nitrogen Removal; Control; Denitrification; Fuzzy logic; low-cost sensors; Nitrification.

\section{Introduction}

The increasing problems of eutrophication and hypoxia have led to upgrading wastewater treatment plants (WWTPs) in order to perform nutrient removal processes. These processes considerably increase the complexity of wastewater treatment plant operation, taking the significant number of factors that influence their performance and the strong dynamics of a WWTP into account. All these factors emphasize the importance of instrumentation control and automation of nutrient removing WWTPs in order to meet increasingly stringent effluent criteria with the lowest operational costs.

Dissolved oxygen (DO) is one of the most important parameters to be controlled in the activated sludge process. Since 1970, a considerable number of control algorithms have been proposed, from on/off aeration controllers to more sophisticated ones such as complex model predictive controllers or fuzzy controllers [1-2]. With regard to nutrient removal processes, during the last decade considerable efforts have been made to control these processes. However, at first, the application of control systems to nutrient removal processes was limited due to the characteristics of the first on-line nutrient analyzers developed, such as their high cost, complex maintenance, and questionable reliability. Currently, on-line nitrogen sensors have been greatly improved [3] and different control strategies are being developed/assessed [4-6]. The most common technique for controlling the nitrification process is by modifying the dissolved oxygen concentration in the aerobic reactor based on the ammonium concentration in that reactor [3-4,7-9]. The denitrification process is usually controlled by modifying the 
internal recycle flow rate and/or the external carbon dosage based on the nitrate concentration in the anoxic reactor and/or the aerobic reactor $[8,10,11]$. Thus, currently nitrogen control systems are mainly based on on-line nitrogen sensors/analyzers [12]. The major disadvantage of the nitrogen sensors/analyzers is their relatively high investment and maintenance costs, and their complex operation [13-17]. Indeed, a continuous supervision of these on-line nitrogen sensors/analyzers is needed in order to obtain a proper performance. Hence, these features reduce the implementation possibilities of nitrogen control systems based on nitrogen analyzers in small and medium WWTPs. Since increasingly stringent nitrogen standards are being imposed to these reduced-size WWTPs, new monitoring and control strategies (more robust, straightforward and affordable) are needed.

During the last decade, many researchers have considered the use of oxidation-reduction potential (ORP), $\mathrm{pH}$, and dissolved oxygen (DO) for monitoring and controlling the biological nitrogen removal processes. Specifically, these sensors have been widely applied to control the nitrogen removal process in sequencing batch reactors and intermittently aerated continuous systems [18-26]. These control strategies are based on the so-called bending points of the ORP and $\mathrm{pH}$ profiles. Thus, the $\mathrm{pH}$ variation provides an indication of the ongoing biological processes, i.e., an increase in $\mathrm{pH}$ is caused by denitrification, and a decrease in $\mathrm{pH}$ is caused to nitrification (see e.g. [24]). On the other hand, anaerobic/anoxic and aerobic conditions can be detected by the ORP profile since it reflects the dissolved oxygen concentration in the system (see e.g. [27]). These simple sensors offer an attractive alternative to nitrogen analyzers because they are characterized by low investment and maintenance costs and a straightforward operation. However, their application to nitrogen control in continuous systems is still being evaluated [13]. Significant information about the nitrification and denitrification processes in continuous systems can be obtained from the $\mathrm{pH}$ and ORP sensors located either in different points along a plug flow reactor or in different mixed tanks in series [16]. Since the information provided by these low-cost sensors consists in indirect measures of the nitrification and denitrification processes, advanced control algorithms must be used to benefit from the use of these sensors. Fuzzy logic offers an effective tool for the development of such intelligent control systems [28]. Fuzzy control algorithms can be used to create transparent controllers that are easy to modify and extend because the fuzzy-rules are written in the language of process experts and operators [11].

The main goal of this work was to develop a competitive and feasible nitrogen control strategy for continuous systems based on $\mathrm{pH}$ and ORP sensors. This nitrogen control strategy comprises two independent fuzzy logic-based controllers: the nitrification process controller and the denitrification process controller. Both controllers have been tested and evaluated in a nutrient removing pilot plant fed with full-scale wastewater.

\section{Materials and methods}

\subsection{Pilot plant description and wastewater characterization}

The nitrogen control strategy was developed and tested in a nutrient removing pilot plant based on a UCT scheme [16, 29]. This pilot plant is located in the Carraixet WWTP in the area of Valencia (Spain), which receives urban wastewater with a small contribution of industrial effluents. The lay-out of the pilot plant as well as the main 
instrumentation implemented is shown in Figure 1.

The wastewater fed into the pilot plant was pumped from the primary clarifier of the full-scale WWTP with an influent flow rate of $80 \mathrm{~L} \cdot \mathrm{h}^{-1}$. Additionally, an external carbon source addition in the form of acetate was used to compensate for the low COD of the influent. Table 1 shows the average wastewater characteristics of the influent and effluent of the pilot plant.

The uncertainty associated to the experimental values shown in Table 1 , includes the standard deviation of the different samples analyzed along the experimental period as well as the coefficient of variation associated to the analytical methods. Important to note is that the main contribution to this uncertainty is the standard deviation, whose high values reveal the significant variability of the influent load. The BNR pilot plant basically consists of an activated sludge reactor $(800 \mathrm{~L})$ and a secondary clarifier. As Figure 1 shows, the reactor is split into twelve reaction volumes in series that are separated by removable baffles so as to modify the volume ratio of anaerobic, anoxic, and aerobic zones. Hence, the pilot plant design is very flexible and allows for a wide range of operational schemes to be tested. In this work, the first volume (R1 in Figure 1) worked as a homogenization tank. Reactors R3 to R4 were operated as anaerobic zones, with a total volume of $166 \mathrm{~L}$. Reactors R5 to R7 were operated as anoxic zones, with a total volume of 249 L. Finally, reactors R8 to R13 were operated as two aerobic zones (without separation baffles): the first aerobic zone comprises reactors R8 to R9 with a total volume of $129 \mathrm{~L}$; and the second aerobic zone comprises reactors R10 to R13 with a total volume of $256 \mathrm{~L}$. All the operating flow rates, (based on Figure 1) are illustrated in Table 2.

\subsection{Monitoring system description.}

A significant number of nitrogen and low-cost sensors were installed in the pilot plant in order to obtain on-line information about the state of the process (see Figure 1). All these sensors are labeled using the number of the reactor where each sensor is located, i.e., $\mathrm{pH} 5$ indicates the $\mathrm{pH}$ sensor located in reactor $\mathrm{R} 5$. The sensors installed were connected to a network system that included several transmitters, a PLC, and a personal computer to perform multi-parameter control and data acquisition. A Supervisory Control And Data Acquisition (SCADA) software was developed to monitor all the signals from the sensors. The on-line sensors (all of them from Hach-Lange) were classified as either low-cost sensors ( $\mathrm{pH}$, ORP and DO) or nutrient analyzers (ammonium and nitrate). The nitrogen analyzers implemented in the pilot plant were: one nitrate analyzer placed in the last anoxic reactor (NO7, Nitratax plus model), another nitrate analyzer placed in the last aerobic zone (NO12, Evita 5100 model), and one ammonium analyzer placed in the last aerobic zone (NH12, Amtax sc model). Nitrate analyzers and ammonium analyzers measured nitrogen concentration as $\mathrm{NO}_{3}-\mathrm{N}$ and $\mathrm{NH}_{4}-\mathrm{N}$, respectively. The on-line measurements provided by the low-cost sensors were used as input data for the developed nitrogen control strategy. Specifically, for the nitrification controller, the input data corresponded to the measurements provided by the $\mathrm{pH}$ sensors (pHD-S sc pH model) that were located in the end of the first aerobic zone (pH9) and in the end of the last aerobic zone (pH13). Likewise, for the denitrification controller, the input data were the measurements provided by the $\mathrm{pH}$ sensors that were located in the first anoxic zone (pH5) and in the last anoxic zone (pH7) and the ORP sensors (pHD-S sc ORP model) that were located in the last anoxic zone (ORP7) and in the last anaerobic zone (ORP4). The DO sensor was placed in the last aerobic zone 
(DO13, Hach LDO).

In contrast, the on-line measurements of the nitrogen analyzers were used to calibrate the control system performance and to verify the information about the nitrification and denitrification processes provided by the ORP and $\mathrm{pH}$ sensors. During this period, in order to confirm the reliability of the nitrogen analyzers used to calibrate the control system performance, the nitrogen analyzers output data were compared to the corresponding laboratory conformance data. Moreover, an exhaustive maintenance of the analyzers was needed in order to assure their proper performance. The regular maintenance of low-cost sensors was quite simple and consisted of replacing the salt bridge and the buffer once a year (for the ORP and $\mathrm{pH}$ sensors), and calibrating these sensors with a frequency of two weeks. The DO13 sensor required neither calibration nor maintenance by the operator. The main features of all these sensors and the monitoring system are described in more detail in [16].

\subsection{Sampling and laboratory measurements.}

Composite samples were regularly collected throughout the day from the influent and effluent of the pilot plant. Grab samples from the last zone of each anaerobic, anoxic, and aerobic reactor were also collected. The following parameters were analyzed for the influent and effluent streams: total suspended solids (TSS), volatile suspended solids (VSS), total and soluble chemical oxygen demand (TCOD and SCOD), total and soluble biological oxygen demand (TBOD and SBOD), volatile fatty acids (VFA), ammonia nitrogen $\left(\mathrm{NH}_{4}-\mathrm{N}\right)$, nitrate nitrogen $\left(\mathrm{NO}_{3}-\mathrm{N}\right)$, total nitrogen $(\mathrm{TN})$, filtered total nitrogen ( $\left.\mathrm{TN}_{\text {filtered}}\right)$, orthophosphate $\left(\mathrm{PO}_{4}-\mathrm{P}\right)$, total phosphorus (TP), and alkalinity (Alk). For the characterization of the activated sludge, TSS, VSS, TCOD, VFA, $\mathrm{NH}_{4}-\mathrm{N}, \mathrm{NO}_{3}-\mathrm{N}$, $\mathrm{TN}_{\text {filtered, }} \mathrm{PO}_{4} \mathrm{P}$, and $\mathrm{TP}$ were determined. Solids, COD, nitrogen, and phosphorus determinations were performed according to Standard Methods [30]. The carbonate alkalinity and VFA concentration were determined by titration according to the method proposed by [31]. BOD was determined by pressure measurements using a WTW Oxitop Control 100 system.

Special samples were collected to verify that the test instrument output data from the nitrogen analyzers (NH12, NO7 and NO12) were similar to the corresponding laboratory conformance data. Since the control system calibration was carried out using data from the nitrogen analyzers, a proper performance of these analyzers was guaranteed by an exhaustive analytical campaign and an intensive maintenance of the analyzers during this period.

\subsection{Control system description.}

The fuzzy logic-based control system comprises two independent controllers: the nitrification process controller and the denitrification process controller. The nitrification controller works as a supervisory control of the aeration control system so as to optimize the nitrification process without an excess in the air supply. The denitrification controller acts by modifying the internal recycle flow rate from the aerobic to the anoxic reactor in order to comply with the nitrogen effluent criteria with the minimum pumping energy consumption. Both control algorithms were designed based on the knowledge gained from the evaluation of the relations between the $\mathrm{pH}$ and ORP sensors and the performance of the nitrification/denitrification processes (see [16]). It was observed that the nitrification process can be evaluated by measuring the 
$\mathrm{pH}$ difference between the first and the last aerobic zones. It was also observed that the denitrification process can be evaluated by measuring the $\mathrm{pH}$ difference between the first and the last anoxic zones, the ORP in the last anoxic zone and the ORP in the last anaerobic zone. It was assumed that a drop in the $\mathrm{pH}$ (i.e., a positive $\mathrm{pH}$ difference) indicates a proper nitrification process throughout the aerobic reactor without an excess in the air supply. Similarly, a complete denitrification process in the anoxic reactor can be estimated by an increase in the $\mathrm{pH}$ throughout the anoxic reactor, together with low values of ORP in the last anoxic zone (i.e. ORP values similar to the ORP values of the last anaerobic reactor). To develop a control system in which all this information could be interpreted similarly to human reasoning, several fuzzy sets and variables were defined and combined in a fuzzy logic-based control system. This control system can be applied to WWTPs with a configuration of plug flow reactors or completely mixed reactors that include at least two separated zones.

\subsubsection{Nitrification process control strategy.}

Figure 2a shows a flow diagram of this control system in the pilot plant. The nitrification control strategy consists of two types of fuzzy controllers at different hierarchy levels: a supervisory control system that commands the oxygen set point value of the second aerobic zone (DO13 $\left.{ }_{S P}\right)$ and an oxygen controller that maintains the dissolved oxygen concentration DO13, close to the commanded set point value by manipulating the rotational speed of the blower (SO1) with a frequency converter (VF1). The oxygen set point value is modified depending on the value of the $0.5 \mathrm{~h}$ mobile-average of the aerobic $\mathrm{pH}$ difference. This aerobic $\mathrm{pH}$ difference is calculated as the difference between the $\mathrm{pH}$ at the end of the first aerobic zone and the $\mathrm{pH}$ at the end of the last aerobic zone:

$$
d p H_{M a}=p H 9-p H 13
$$

The 0.5h mobile-average window is a simple mathematical concept that filters the typical variations in the measurements of $\mathrm{pH}$ by the daily load profile and it is usually applied to nitrogen control systems (see e.g. [9]). This aerobic $\mathrm{pH}$ difference indicates the extension of the nitrification process in the aerobic reactor showing whether the nitrification process is limited by the oxygen concentration (a positive $\mathrm{pH}$ difference) or there is an excess in the air supply (a negative $\mathrm{pH}$ difference), as shown in a previous work [16]. The fuzzy nitrification controller appropriately modifies the oxygen set point value in order to maintain the $\mathrm{pH}$ difference close to a predefined set point value $\left(d p H_{S P}\right)$. This set point value must be previously calibrated for each WWTP. It corresponds to a $\mathrm{pH}$ difference value at which the nitrification process takes place throughout the aerobic reactor, which implies an effluent ammonium concentration lower than a certain desired value without an excess in the air supply. Specifically, in this case study, the $d p H_{S P}$ was calibrated at a value at which ammonium effluent concentration was lower than $0.5 \mathrm{mg} \cdot \mathrm{l}^{-1}$. $\mathrm{pH}$ difference values higher than the calibrated $d p H_{S P}$ value implies that the process needs further aeration to achieve the desired nitrification efficiency. In contrast, $\mathrm{pH}$ difference values lower than the corresponding set point value implies that there is an excess in the air supply. Thus, the nitrification controller increases or decreases the oxygen set point value when the control variable $\left(d p H_{M a}\right)$ is higher or lower than its corresponding set point value $\left(d p H_{S P}\right)$, respectively. 


\subsubsection{Denitrification process control strategy.}

Figure 2b illustrates a flow diagram of this control system implemented in the pilot plant. The proposed denitrification control strategy acts by modifying the internal recycle flow rate from the aerobic reactor to the anoxic one $\left(Q_{B M 3}\right)$ to comply with the nitrogen effluent criteria with the minimum pumping energy consumption. This internal recycle flow rate is modified depending on the following values: the $0.25 \mathrm{~h}$ mobileaverage $\mathrm{pH}$ difference between the last anoxic zone and the first anoxic zone, which is calculated as

$$
d p H_{M x}=p H 7-p H 5
$$

the redox potential measurement in the last anoxic zone (ORP7), and the difference between the redox potential measurement in the last anaerobic zone (ORP4) and the redox potential measurement in the last anoxic zone (ORP7), $d O R P$. The values of $d p H_{M x}$ reveal the extent of the denitrification process in the anoxic reactor. The ORP7 values indirectly indicate the nitrate concentration in this zone, and the redox difference dORP shows the proximity to anaerobic conditions in the last anoxic zone [16]. This control system only increases the internal recycle flow rate when the nitrate concentration in the last anoxic zone is low and the anoxic reactor shows further denitrification capacity. The low nitrate concentration in the last anoxic zone is interpreted by the ORP measurements (ORP7 and ORP4), and the denitrification capacity is interpreted by the tendency of the anoxic $\mathrm{pH}$ difference values $\left(\mathrm{dpH}_{\mathrm{Mx}}\right)$ over time. An upward trend in the $d p H_{M x}$ values over time shows an increase in the denitrification degree in the anoxic reactor.

\subsubsection{Description of fuzzy controllers.}

Both nitrification and denitrification controllers are fuzzy logic-based controllers that consist of five stages.

Firstly, stage 1 represents the input step where the input variables are calculated. The input variables to the nitrification controller are the aerobic $\mathrm{pH}$ difference error $\left(\varepsilon_{d p H_{M}}\right)$, which is calculated as

$$
\varepsilon_{d p H_{M}}=d p H_{S P}-d p H_{M a}
$$

and the change of this $\mathrm{pH}$ difference error value over time $\left(\Delta \varepsilon_{d p H_{M}}\right)$, which is calculated as

$$
\Delta \varepsilon_{d p H_{M}}=\left|\varepsilon_{d p H}\right|_{t}-\left|\varepsilon_{d p H}\right|_{t-R T}
$$

where the variable $\left|\varepsilon_{d p H_{M}}\right|_{t}$ corresponds to the $\mathrm{pH}$ difference error calculated in each control action, and the variable $\left|\varepsilon_{d p H}\right|_{t-R T}$ corresponds to the $\mathrm{pH}$ difference error calculated in the previous control action ( $R T$ is the response time of the controller, i.e., the time interval between two control actions). This second input variable is used to evaluate the tendency of the control variable, the aerobic $\mathrm{pH}$ difference $\left(\mathrm{dpH}_{\mathrm{Ma}}\right)$, which gives valuable information for accurately controlling the nitrification process. 
The input variables to the denitrification controller are the following three variables: the change of the anoxic $\mathrm{pH}$ difference values over time, which is calculated as

$$
\Delta d p H_{M}=d p H_{M x}-d p H_{M x, b a c k}
$$

where the variable $d p H_{M x, b a c k}$ corresponds to the $3 \mathrm{~h}$ mobile-average anoxic $\mathrm{pH}$ difference (the $d p H_{M x}$ variable is the $0.25 \mathrm{~h}$ mobile-average anoxic $\mathrm{pH}$ difference); the redox measurement in the last anoxic reactor, ORP7; and the redox difference between the redox measurement in the last anaerobic reactor and the redox measurement in the last anoxic reactor, which is calculated as

$$
d O R P=O R P 4-O R P 7
$$

Once the input variables are calculated, in stage 2, the so-called fuzzification, the input variables are converted into linguistic variables (fuzzy set), which are represented by membership functions (Gaussian shape in this study). The Gaussian membership functions are defined by the following equation:

$$
\mu(p)=\exp \left(-\frac{(p-c)^{2}}{2 \cdot \sigma^{2}}\right)
$$

where $p$ is the numerical value of the variable; and $c$ and $\sigma$ are the centre and amplitude of the Gaussian membership function, respectively. Both controllers use three Gaussian membership functions to fuzzify each input variable of each controller ("High Negative”, HN; "Low Negative”, LN, and "Low Positive”, LP; or "High Negative”, HN; “Zero”, Z, and "High Positive”, HP).

The output variable of the nitrification controller and the output variable of the denitrification controller are the increment or decrement of the oxygen set point value, $\triangle D O 13_{S P}$, and the increment or decrement of the internal recycle flow rate, $\Delta Q_{B M 3}$, respectively. To defuzzify the output variable of the nitrification controller and the output variable of the denitrification controller, five and four Gaussian membership functions were used, respectively ("High Negative”, HN; “Low Negative”, LN; “Zero”, Z; “Low Positive”, LP, and “High Positive”, HP).

In stage 3, the so-called inference engine, a set of rules is applied to the fuzzy set obtained in stage 2 . Table 3 and Table 4 present the set of inference rules of the nitrification and denitrification controllers, respectively.

The output linguistic variables are obtained in this stage by the Max-Prod operator, following Larsen's fuzzy inference method [32]. Thus, for each rule defined in Table 3 and Table 4, the following operator was applied:

$$
\mu_{\text {rule }, i}=\prod_{1}^{j} \mu_{j}
$$

where $j$ represents each of the input fuzzy sets involved in the rule $i$. Similarly, in order to establish only one output linguistic value when the consequences of different rules are the same, the following operator was applied: 


$$
\mu_{k}=\operatorname{Max}\left(\mu_{\text {rule, } i}\right)
$$

In stage 4, the so-called defuzzification, these linguistic variables are converted into the corresponding numerical control actions. Hence, in order to obtain a single output value (P) from the output fuzzy linguistic set, the Height Defuzzifier method was employed [33], applying the following equation:

$$
P=\frac{\sum_{i=1}^{n} c_{i} \cdot \mu\left(p_{i}\right)}{\sum_{i=1}^{n} \mu\left(p_{i}\right)}
$$

Finally, the stage 5 corresponds to the output stage where the numerical control action of the nitrification controller and denitrification controller are obtained, that is, the oxygen set point value, $D O 13_{S P}$, and the internal recycle flow rate, $Q_{B M 3}$, respectively. The interval values defined for each output variable correspond to [1.5• $Q_{\text {influent, }}$ 4. Q influent], for the manipulated variable $Q_{\mathrm{BM}}$, where $Q_{\text {influent }}$ is the influent flow rate; and to $[1,4] \mathrm{mg}^{-1} \mathrm{l}^{-1}$ for the manipulated variable $D O 13_{S P}$.

\subsection{Control system calibration}

After the definition of both fuzzy controllers, one of the most important steps is their calibration. The iterative calibration procedure carried out is illustrated in Figure 3. Once the initial values of the controller parameters were selected, the calibration procedure was conducted under different operational conditions of temperature (T), biomass concentration (represented by VSS in the reactor), and influent ammonium concentration $\left(\mathrm{NH}_{4}-\mathrm{N}_{\text {infl) }}\right.$ ). The control system calibration took advantage of the strong dynamics observed in the pilot plant (similar to the typical dynamics of full-scale WWTPs), which was mainly caused by the significant variability of the influent load (see Table 1). Thus, several experiments with significant changes in each operational condition ( $\mathrm{T}, \mathrm{NH}_{4}-\mathrm{N}_{\text {infl, }}$, and VSS) were carried out. With regard to the temperature, at first the pilot plant was operated at a controlled temperature of $20^{\circ} \mathrm{C}$ and then, the pilot plant was operated at ambient temperature. The average of the influent ammonium concentration was increased in several experiments to $110 \mathrm{mg} \cdot \mathrm{l}^{-1}$, adding a concentrated ammonium solution in the form of $\mathrm{NH}_{4} \mathrm{Cl}$. Concerning to the biomass concentration, in several experiments the effect of a sharp decrease in this parameter was simulated by setting the sludge recycle flow rate to cero during short time periods (i.e. by accumulating the sludge in the secondary clarifier), which caused a decrease in the MLVSS concentration. To ensure that all these experiments will cause the least possible damage to the biological process of the pilot plant, the sludge retention time was set at 9 days along the experimental period, which corresponded to about $1500 \mathrm{mg} \cdot \mathrm{l}^{-1} \mathrm{SSV}$. Under each operational condition, an analytical monitoring of the influent, effluent, and mixed liquor at the end of each reactor of the pilot plant was performed and the control system performance was assessed. Then, a proper fine-tuning of the controller parameters was made by evaluating the control system behavior. Finally, when the control system performance was considered suitable for different operational conditions, the validation process was completed. The main parameters tuned from the two fuzzy controllers were the defuzzification parameters and the response time, as well as the aerobic $\mathrm{pH}$ difference set point value $\left(d p H_{S P}\right)$ for the nitrification controller. This $d p H_{S P}$ value was found as an important parameter to be adjusted since it will probably depend 
on each specific WWTP and influent wastewater characteristics.

\section{Results and discussion}

\subsection{Nitrification process control performance}

Figure 4illustrates the nitrification controller performance and the aeration controller performance, during the control system calibration. This figure shows the controller performance for three different experiments where the operational conditions of temperature, biomass concentration, and influent ammonium concentration were modified, respectively. The mean values of the operational conditions set at each experiment are shown in Table 5.

The nitrification controller performance is represented by the profiles of the control variable, the corresponding set point, and the manipulated variable, i.e., the aerobic $\mathrm{pH}$ difference $\left(\mathrm{dpH} \mathrm{H}_{\mathrm{Ma}}\right)$, the aerobic $\mathrm{pH}$ difference set point $\left(\mathrm{dpH} \mathrm{H}_{\mathrm{SP}}\right)$, and the dissolved oxygen set point $\left(D O 13_{S P}\right)$, respectively. In addition, the values of the $0.5 \mathrm{~h}$ mobileaverage ammonium concentration in the last aerobic zone are shown. Similarly, the aeration controller performance is graphed by the profiles of the control variable (the dissolved oxygen concentration, DO13), the dissolved oxygen set point (DO13sP) commanded by the nitrification controller, and the manipulated variable (the frequency of the blower (Freq)).

In most cases, Figure 4 shows that the nitrification controller maintained the control variable close to its corresponding set point value most of the time, appropriately moving the manipulated variable, the oxygen set point value. When the control variable was higher than its corresponding set point value, the ammonium monitored concentration was close to $0.5 \mathrm{mg} \cdot \mathrm{l}^{-1}$ or higher than $0.5 \mathrm{mg} \cdot \mathrm{l}^{-1}$, and consequently the nitrification controller increased the manipulated variable. Likewise, when the control variable was equal or lower than its set point value, the control system acted immediately by reducing the aeration supply in order to minimize the energy consumption. In some cases the control variable was not close to its corresponding set point because the manipulated variable had reached is maximum/minimum value (see for instance Figure 4 (f) at 10 hours).

With regard to the aeration controller performance, this figure shows that this control system is able to maintain the dissolved oxygen at its set point value, by appropriately modifying the operational frequency of the blower.

Some aspects must be highlighted for each case presented. The first aspect, as Figure 4b shows, is the sharp increase in the dissolved oxygen in the last aerobic zone at 100 hours, under the minimum frequency of the blower. This event, which was caused by an abrupt descent of the influent load, was also detected by the nitrification controller performance (see Figure 4a), where the control variable reached negative values, which indicates the excess of air supply in the aerobic reactor.

The second aspect, is the sharp descent of the volatile suspended solids concentration in the reactor (see Table 5), from 25 to 34 hours in Figure 4c. As it has been commented before, this low volatile suspended solids concentration was caused by setting the sludge recycle flow rate to cero and accumulating the sludge in the secondary clarifier. Figure 4c also illustrates that, from 25 to 34 hours, the aerobic $\mathrm{pH}$ difference trend did 
not follow the monitored ammonium values trend. This behavior demonstrates that the nitrification process was more limited by the reduced suspended solids concentration than the oxygen concentration. In this case, the developed nitrification controller did not sharply increase the dissolved oxygen set point, as the nitrification controller based on an ammonium analyzer would have done. Consequently, the developed nitrification control system reduces the aeration energy consumption more than using an ammonium analyzer, since the aerobic $\mathrm{pH}$ difference can indicate if the nitrification process is limited by the oxygen concentration or by other factors such as the biomass concentration, temperature and so on. Thus, in this case an increase in the air supply would not have reduced the effluent ammonium concentration.

The third aspect, as Figure 4e shows, is the nitrification controller performance under high influent ammonium concentrations. From 6 to 9 hours and from 30 to 33 hours, the

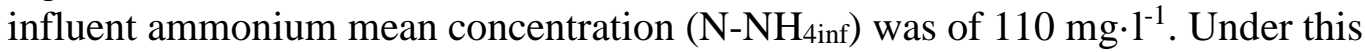
considerable ammonium load, the control system acted immediately by increasing the oxygen set point value, even before the monitored ammonium concentration values reached their maximum. Therefore, the control actions are suitable, reducing the high influent ammonium concentration to a maximum value of only 2 and $1 \mathrm{mg} \cdot \mathrm{l}^{-1}$, respectively. At 32 hours, the control system did not continue to increase the manipulated variable, despite the fact that the control variable was much higher than its set point value. For this period, the nitrification controller did not increase the oxygen set point value because the aeration controller reached its maximum capacity (maximum frequency of the blower), as can be seen in Figure 4f. At 35 hours, when the aeration controller was able to achieve the oxygen set point commanded, the nitrification controller increased the manipulated variable, until the tendency of the control variable started to decrease (from 36 hours). At that point, the control system rapidly reduced the manipulated variable, even quicker than the downward trend of the control variable. Thus, this control system is able to control and reduce high influent ammonium concentrations with the minimum energy consumption from the aeration system.

Figure 5 illustrates, as an example, the nitrification controller performance and the aeration controller performance after calibration, during summer and winter period.

During summer period the high temperature (around $26^{\circ} \mathrm{C}$ ) favored the nitrification process, as can be seen in Figure 5a with the low ammonium concentration along the period. Thus, the control system maintained the oxygen set point at its minimum value. In contrast, the low temperature of the winter period (mean value of $15^{\circ} \mathrm{C}$ ) affected the nitrification process. During this period, as Figure 5c shows, the control system performance modified appropriately the oxygen set point value in order to minimize the effluent ammonium concentration. However, since the maximum aeration energy supply was achieved from 20 hours, there were some periods where the effluent ammonium concentration was above $0.5 \mathrm{mg} \cdot \mathrm{l}^{-1}$.

In general, Figure 5 shows that the control variable trend, the aerobic $\mathrm{pH}$ difference, is significantly similar to the performance of the monitored ammonium values in the last aerobic reactor. Thus, this behavior demonstrates that the aerobic $\mathrm{pH}$ difference is a suitable variable for controlling the nitrification process in continuous systems.

The developed nitrification process control system is able to maintain the aerobic $\mathrm{pH}$ difference close to the corresponding set point value. Thus, this control system allows the effluent ammonium concentration to be maintained below the effluent criteria 
discharge, when there is no limitation by other factors than aeration, with the minimum energy consumption.

\subsection{Denitrification process control performance}

Figure 6a shows the denitrification controller performance for an experiment carried out under high influent ammonium concentration. Figure 6b shows, for the same time interval as Figure 6a, the monitored values of the $0.5 \mathrm{~h}$ mobile-average nitrate concentration in the last anoxic zone $\left(N O 7_{M}\right)$ and the $0.5 \mathrm{~h}$ mobile-average nitrate concentration in the last aerobic zone $\left(N O 12_{M}\right)$.

From 22 to 25 hours, the influent ammonium concentration to the pilot plant was 110 $\mathrm{mg} \cdot \mathrm{l}^{-1}$. The consequent abrupt increase in the nitrate concentration in the last anoxic zone, shown in Figure 6b, is interpreted in Figure 6a by the sharp increase in the redox potential of the last anoxic zone (ORP7) and by the sharp decrease in the ORP difference value, dORP. During this period, the denitrification controller acted immediately, by reducing the internal recycle flow rate at its minimum value (1.5 times the influent flow rate). For the rest of the period represented in Figure 6, the denitrification controller only increased the nitrate recycle flow rate when the nitrate concentration in the last anoxic zone was lower than $1 \mathrm{mg} \cdot \mathrm{l}^{-1}$ and the change of the anoxic $\mathrm{pH}$ difference over time was higher than cero $\left(\Delta d p H_{M}>0\right)$. The low nitrate concentration in the anoxic reactor is indicated by the low values of ORP7 and the low negative values of the variable dORP. The positive values of the variable $\Delta d p H_{M}$ showed an upward trend in the anoxic $\mathrm{pH}$ difference values over time, which implies an increase in the denitrification degree in the anoxic reactor.

Figure 7 shows, as an example, the denitrification controller performance after calibration during summer and winter period, respectively. Figure 7a shows that the effluent nitrate concentration as well as the nitrate concentration at the end of the anoxic reactor was really low, mainly due to the high ambient temperature. Since the anoxic $\mathrm{pH}$ difference over time was around or lower than cero, the denitrification controller maintained the nitrate recycle flow rate at its minimum value. From 40 hours (Figure 7b) the nitrate concentration at the end of the anoxic reactor started to increase mainly because there was not enough COD in the anoxic reactor to totally denitrify the influent nitrate concentration.

During winter period, as Figure 7c shows, the denitrification controller increased the nitrate recycle flow rate from 10 to 30 hours, and as a result, the effluent nitrate concentration decreased. The rest of the period, the nitrate recycle flow rate was generally maintained at its minimum value because the anoxic reactor was not able to denitrify all the influent nitrate concentration.

Therefore, the developed denitrification controller maintains a low nitrate concentration in the last anoxic zone, when there is not limitation by COD, which minimizes the nitrate recirculation to the anaerobic reactor. Moreover, this controller minimizes the energy consumption derived from pumping because it only increases the internal recycle flow rate when both the anoxic reactor reveals further capacity for denitrification and the nitrate concentration in the last anoxic reactor is lower than 1 $\mathrm{mg} \cdot \mathrm{l}^{-1}$.

\section{Conclusions}


The proposed fuzzy logic-based control system confirms the applicability of $\mathrm{pH}$ and ORP sensors for controlling biological nitrogen removal in continuous systems. This control system reduces the aeration energy consumption more than using an ammonium analyzer, since the $\mathrm{pH}$ difference can indicate if the nitrification process is limited or not by the oxygen concentration. Furthermore, it minimizes the energy consumption derived from pumping because the control system only increases the internal recycle flow rate when the anoxic reactor reveals further capacity for denitrification. Overall, the results obtained show a promising applicability of the developed control system at an industrial scale in nutrient removing WWTPs.

\section{Acknowledgements}

The authors would like to express their gratitude to the Ministry of Science and Education for the financial support (Project reference CTM2005-06919-C0301/TECNO). Financial support from Entitat Pública de Sanejament d’Aigues Residuals de la Comunitat Valenciana and Depuración de Aguas del Mediterráneo is also gratefully acknowledged.

\section{References}

[1] G. Olsson, M. Nielsen, Z. Yuan, A. Lynggaard-Jensen, J.P. Steyer, Instrumentation, Control and Automation in Wastewater Systems, IWA Publishing, London, 2005.

[2] A. Traoré, S. Grieu, S. Puig, L. Corominas, F. Thiery, M. Polit, J. Colprim, Fuzzy control of dissolved oxygen in a sequencing batch reactor pilot plant, Chem. Eng. J. 111(1) (2005) 13-19.

[3] U. Jeppson, J. Alex, M.N. Pons, H. Spanjers, P.A. Vanrolleghem, Status and future trends of ICA in wastewater treatment a European perspective, Water Sci. Technol. 45(4-5) (2002) 485-494.

[4] D. Vrecko, N. Hvala, A. Stare, O. Burica, M. Strazar, M. Levstek, P. Cerar, S. Podbevsek, Improvement of ammonia removal in activated sludge process with feedforward-feedback aeration controllers. Water Sci. Technol. 53(4-5) (2006) 125-132.

[5] S. Wang, S. Zhang, C. Peng, T. Akio, Intercross real-time control strategy in alternating activated sludge process for shortcut biological nitrogen removal treating domestic wastewater. J. Environ. Sci. 20(8), (2008) 957-963.

[6] J. Guerrero, A. Guisasola, R. Vilanova, J.A. Baeza, Improving the performance of a WWTP control system by model-based setpoint optimization, Environ Modell Softw. 26(4), (2011) 492-497.

[7] P. Ingildsen, Releasing full-scale Control in Wastewater Treatment Systems using in situ Nutrient Sensors, PhD thesis, Lund University, 2002.

[8] J. Serralta, J. Ribes, A. Seco, J. Ferrer, A supervisory control system for optimizing nitrogen removal and aeration energy consumption in wastewater treatment plants. Water Sci. Technol. 45(45), (2002) 309-316.

[9] E. Ayesa, A. De la Sota, P. Grau, J.M. Sagarna, A. Salterain, J. Suescun, Supervisory control strategies for the new WWTP of Galindo-Bilbao: the long run from the conceptual design to the fullscale experimental validation, Water Sci. Technol. 53(4-5) (2006) 193-201.

[10] Z. Yuan, A. Oehmen, P. Ingildsen, Control of nitrate recirculation flow in pre-denitrification systems. Water Sci. Technol. 45(4/5) (2002) 29-36.

[11] M. Yong, P. Yong-zhen, W. Xiao-lian, W. Shu-ying, Intelligent control aeration and external carbon addition for improving nitrogen removal. Environ Modell Softw. 21(6) (2006) 821-828.

[12] P. Ingildsen, G. Olsson, Exploiting on line in-situ ammonium, nitrate and phosphate sensors in a full-scale wastewater plant operation, Water Sci. Technol. 46(4-5) (2002) 139-147.

[13] Y. Z. Peng, Y. Ma, S.Y. Wang, Improving nitrogen removal using on-line sensors in the A/O process. Biochem. Eng. J. 31(1) (2006) 48-55.

[14] M. Ekman , B. Björlenius , M. Andersson , Control of the aeration volume in an activated sludge process using supervisory control strategies, Water Res. 40(8), (2006) 1668-1676.

[15] T.M. Palmer, M.C. Ross, S.G. Nutt, S. Kharkar, On line nitrogen monitoring and control strategies. Report 03-CTS-8, Water Environment Research Foundation, WERF, 2007. 
[16] M.V. Ruano, J. Ribes, A. Seco, J. Ferrer, Low cost-sensors as a real alternative to on-line nitrogen analysers in continuous systems. Water Sci. Technol. 60(12) (2009) 3261-3268.

[17] C. Muñoz, D. Rojas, O. Candia, L. Azocar, C. Bornhardt, C. Antileo, Supervisory control system to enhance partial nitrification in an activated sludge reactor. Chem. Eng. J. 145(3) (2009) 453-460.

[18] E. Paul, S. Plisson-Saune, M. Mauret, J. Cantet, Process state evaluation of alternating Oxic-Anoxic Activated Sludge using ORP, pH and DO. Water Sci. Technol. 38(3) (1998) 299-306.

[19] Y. Ruey-Fang, L. Shu-Liang, C. Wan-Yuan, C. Cheng-Nan, Performance enhancement of SBR applying real-time control. J. Environ. Eng. 126(10) (2000) 943-948.

[20] Y. Z. Peng, Y. Ma, S.Y. Wang, Improving nitrogen removal using on-line sensors in the A/O process. Biochem. Eng. J. 31(1) (2006) 48-55.

[21] N. Kishida, J-H. Kim, M. Chen, H. Sasaki, S. Ryunichi, Effectiveness of Oxidation-Reduction Potential and $\mathrm{pH}$ as Monitoring and control parameter for nitrogen removal in swine wastewater treatment by sequencing batch reactors, J. Biosci. Bioeng. 96(3) (2003) 285-290.

[22] B.S. Akın, A. Ugurlu, Monitoring and control of biological nutrient removal in a Sequencing Batch Reactor, Process Biochem. 40(8) (2005) 2873-2878.

[23] M. N. Pius, W. Li, K. V. Venkata, Potential strategies for process control and monitoring of stabilization of dairy wastewaters in batch aerobic treatment systems. Process Biochem. 42(9), (2007) 1272-1278.

[24] P. Tanwar, T. Nandy, P. Ukeya, P. Manekara, Correlating on-line monitoring parameters, pH, DO and ORP with nutrient removal in an intermittent cyclic process bioreactor system. Bioresour. Technol. 99(16) (2008) 7630-7365.

[25] D. Gao, Y. Peng, B. Li, H. Liang, Shortcut nitrification-denitrification by real-time control strategies, Bioresour. Technol. 100(7) (2009) 2298-2300.

[26] C.H. Ga, C.S. Ra, Real-time control of oxic phase using $\mathrm{pH}(\mathrm{mV})$-time profile in swine wastewater treatment, J. Hazard.Mater. 172, (2009) 61-67.

[27] H. Kim, O. J. Hao, pH and Oxidation-Reduction Potential Control Strategy for Optimization of Nitrogen Removal in an Alternating Aerobic-Anoxic System, Water Environ. Res. 73(1), (2001) 95102.

[28] G. Zhu, Y. Peng, B. Ma, Y. Wang, C. Yin, Optimization of anoxic/oxic step feeding activated sludge process with fuzzy control model for improving nitrogen removal. Chem. Eng. J. 151(1-3), (2009) 195-201.

[29] M. Henze, M. C. M. van Loosdrecht, G.A. Ekama and D. Brdjanovic, Biological wastewater treatment: Principles, Modelling and Design, IWA Publishing, London, 2008.

[30] Standard Methods for the Examination of Water \& Wastewater, 21st edn, American Public Health Association / American Water Works Association. / Water Environment, Washington DC, USA, 2005.

[31] WRC, Simple titration procedures to determine $\mathrm{H}_{2} \mathrm{CO}^{*}$ alkalinity and short-chain fatty acids in aqueous solutions containing known concentrations of ammonium, phosphate and sulphide weak acid/bases, Report No. TT 57/92, Water Research Commission, University of Cape Town, Pretoria, Republic of South Africa, 1992.

[32] P.M. Larsen, Industrial application of fuzzy logic control, Int. J. Man. Mach. Stud., 12(1) (1980) 310.

[33] J.M. Mendel, Fuzzy logic systems for engineering: A tutorial. In: Proceedings of the IEEE, 83(3) (1995) 345-376. 
Table 1. Average influent and effluent wastewater characteristics

Table 2. Operating flow rates in the pilot plant (using the same nomenclature as in Figure 1)

Table 3. Fuzzy control rules of the nitrification control system.

Table 4. Fuzzy control rules of the denitrification control system.

Table 5. Average values of the operational conditions for the three case studies shown in Figure 5, Figure 6 and Figure 7. 


\begin{tabular}{llll}
\hline Parameter & Unit & Influent & Effluent \\
\hline TSS & $\mathrm{mg} \mathrm{l}^{-1}$ & $128 \pm 31$ & $23 \pm 5$ \\
VSS & mg l$^{-1}$ & $104 \pm 34$ & $14 \pm 3$ \\
TCOD & mgCOD l $^{-1}$ & $406 \pm 92$ & $45 \pm 8$ \\
SCOD & mgCOD l $^{-1}$ & $228 \pm 41$ & $39 \pm 6$ \\
TBOD & mgCOD l $^{-1}$ & $307 \pm 52$ & $12.1 \pm 6.2$ \\
SBOD & mgCOD l $^{-1}$ & $197 \pm 15$ & $7.9 \pm 4.6$ \\
VFA & mgCOD l$^{-1}$ & $99 \pm 14$ & $<5$ \\
$\mathrm{NO}_{3}-\mathrm{N}$ & mgN l $^{-1}$ & $<0.2$ & $6.2 \pm 2.4$ \\
$\mathrm{NH}_{4}-\mathrm{N}$ & $\mathrm{mgN} \mathrm{l}^{-1}$ & $40.2 \pm 7.9$ & $0.4 \pm 0.4$ \\
$\mathrm{TN}_{\mathrm{TN}}$ & $\mathrm{mgN} \mathrm{l}^{-1}$ & $48.7 \pm 8.1$ & $8.3 \pm 2.9$ \\
$\mathrm{TP}^{-1}$ & $\mathrm{mgN} \mathrm{l}^{-1}$ & $42.6 \pm 6.8$ & $6.4 \pm 2.8$ \\
$\mathrm{PO}_{4}-\mathrm{P}$ & $\mathrm{mgP} \mathrm{l}^{-1}$ & $10.3 \pm 2.1$ & $2.6 \pm 2.2$ \\
$\mathrm{Alk}$ & $\mathrm{mgP} \mathrm{l}^{-1}$ & $8.5 \pm 1.8$ & $0.8 \pm 0.6$ \\
\hline
\end{tabular}




\begin{tabular}{lllllll}
\hline & QвM1 & QвM3 & QвM4 & QвM2 & QD1 & QвP2 \\
\hline Flow rates $\left(\mathbf{L} \cdot \mathbf{h}^{-1}\right)$ & 84.0 & 159.6 & 168.0 & 210.0 & 0.6 & 3.3 \\
\hline
\end{tabular}


\begin{tabular}{l} 
Inference Rules \\
IF $\varepsilon_{d p H_{M}}$ is $L P$ and $\Delta \varepsilon_{d p H_{M}}$ is $C$, then $\triangle O D 13_{C}$ is $H N$. \\
IF $\varepsilon_{d p H_{M}}$ is $L P$ and $\Delta \varepsilon_{d p H_{M}}$ is $H P$, then $\Delta O D 13_{C}$ is $H N$. \\
IF $\varepsilon_{d p H_{M}}$ is $L P$ and $\Delta \varepsilon_{d p H_{M}}$ is $H N$, then $\Delta O D 13_{C}$ is $L N$. \\
IF $\varepsilon_{d p H_{M}}$ is $L N$ and $\Delta \varepsilon_{d p H_{M}}$ is $H N$, then $\Delta O D 13_{C}$ is $L N$. \\
IF $\varepsilon_{d p H_{M}}$ is $H N$ and $\Delta \varepsilon_{d p H_{M}}$ is $H N$, then $\Delta O D 13_{C}$ is $L P$. \\
IF $\varepsilon_{d p H_{M}}$ is $L N$ and $\Delta \varepsilon_{d p H_{M}}$ is $H P$, then $\Delta O D 13_{C}$ is $L P$. \\
IF $\varepsilon_{d p H_{M}}$ is $H N$ and $\Delta \varepsilon_{d p H_{M}}$ is $C$, then $\Delta O D 13_{C}$ is $H P$. \\
IF $\varepsilon_{d p H_{M}}$ is $H N$ and $\Delta \varepsilon_{d p H_{M}}$ is $H P$, then $\triangle O D 13_{C}$ is $H P$. \\
IF $\varepsilon_{d p H_{M}}$ is $L N$ and $\Delta \varepsilon_{d p H_{M}}$ is $C$, then $\triangle O D 13_{C}$ is $C$. \\
\hline
\end{tabular} 
Inference Rules

IF ORP7 is $L P$ and $d O R P$ is $H N$, then $\triangle Q_{\text {вмз }}$ is $H N$.

IF ORP7 is $L P$ and $d O R P$ is $L N$, then $\triangle Q_{B M 3}$ is $H N$.

IF ORP7 is $L P$ and $d O R P$ is $L N$ and $\triangle d p H_{M}$ is $H P$, then $\triangle Q_{\text {BM }}$ is $L N$.

IF ORP7 is $L N$ and $d O R P$ is $L N$ and $\triangle d p H_{M}$ is $H N$, then $\triangle Q_{B M 3}$ is $L N$.

IF ORP7 is $H N$ and $d O R P$ is $L P$ and $\triangle d p H_{M}$ is $Z$, then $\triangle Q_{B M 3}$ is $L N$.

IF ORP7 is $L N$ and $d O R P$ is $L P$ and $\triangle d p H_{M}$ is $H P$, then $\triangle Q_{B M 3}$ is $L P$.

IF ORP7 is $H N$ and $d O R P$ is $L P$ and $\triangle d p H_{M}$ is $H P$, then $\triangle Q_{B M 3}$ is $H P$. 


\begin{tabular}{llll}
\hline & $\mathrm{SSV}\left(\mathrm{mg} \cdot \mathrm{l}^{-1}\right)$ & $\mathrm{T}\left({ }^{\circ} \mathrm{C}\right)$ & $\mathrm{NH}_{4}-\mathrm{N}_{\text {infl }}\left(\mathrm{mg} \cdot \mathrm{l}^{-1}\right)$ \\
\hline Figure 5 & 1500 & 20 & 40.0 \\
Figure 6 & {$[400-1520]$} & {$[23-26]$} & 40.0 \\
Figure 7 & {$[1200-1572]$} & {$[23-26]$} & 110.0 \\
\hline
\end{tabular}


Figure 1. Flow diagram of the UCT pilot plant where the control system has been developed.

Figure 2. Flow diagram of the developed nitrogen control system applied to the pilot plant: (a) nitrification controller; (b) denitrification controller.

Figure 3. Calibration steps of the control system.

Figure 4. Nitrification and aeration controller performance for three different experiments during the calibration period: (a) and (b) for experiment at controlled temperature; (c) and (d) for experiments at low biomass concentration; (e) and (f) for experiments at high influent ammonium concentration.

Figure 5. Nitrification and aeration controller performance after calibration: (a) and (b) during summer period; (c) and (d) during winter period.

Figure 6. Calibration experiment for the denitrification controller: (a) denitrification controller performance, and (b) nitrate monitored variables profiles.

Figure 7. Denitrification controller performance and nitrate monitored variables profiles after calibration: (a) and (b) during summer period; (c) and (d) during winter period. 


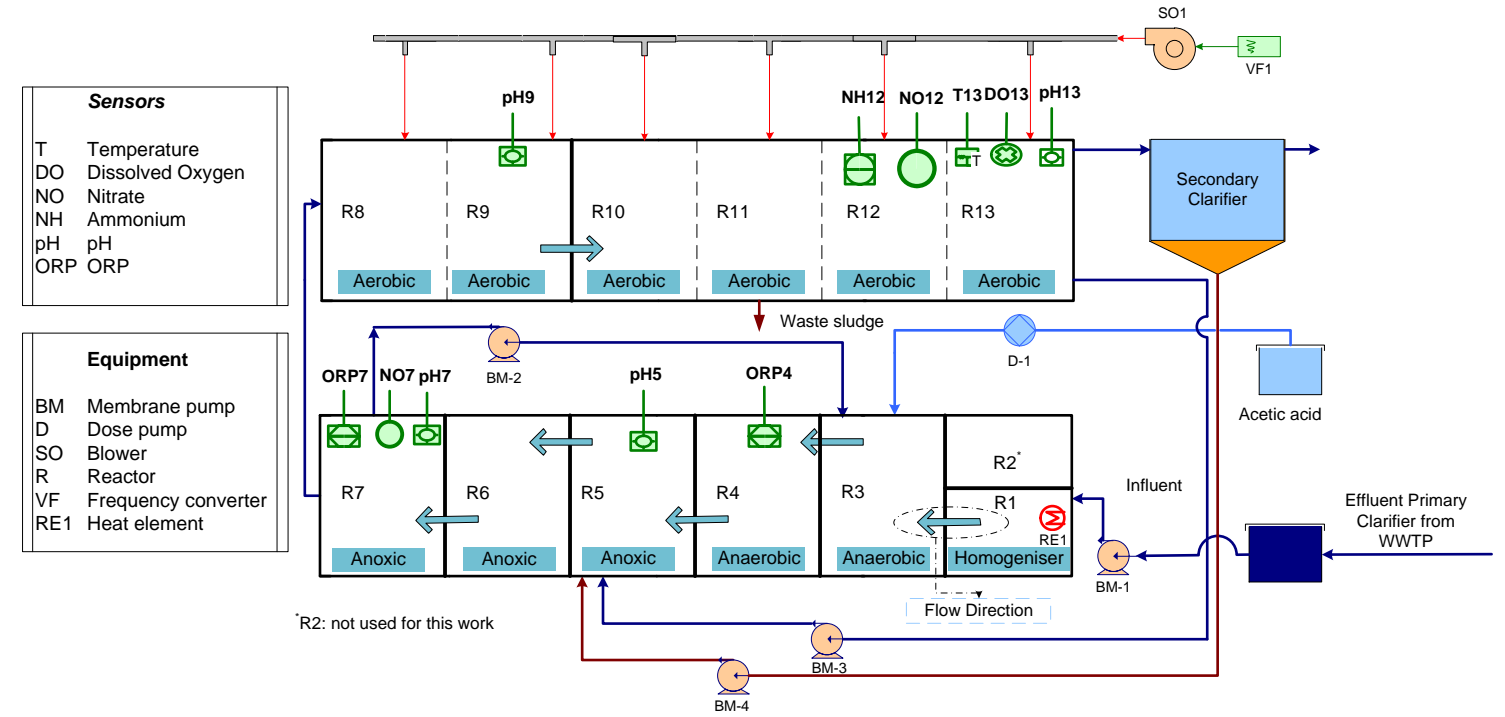




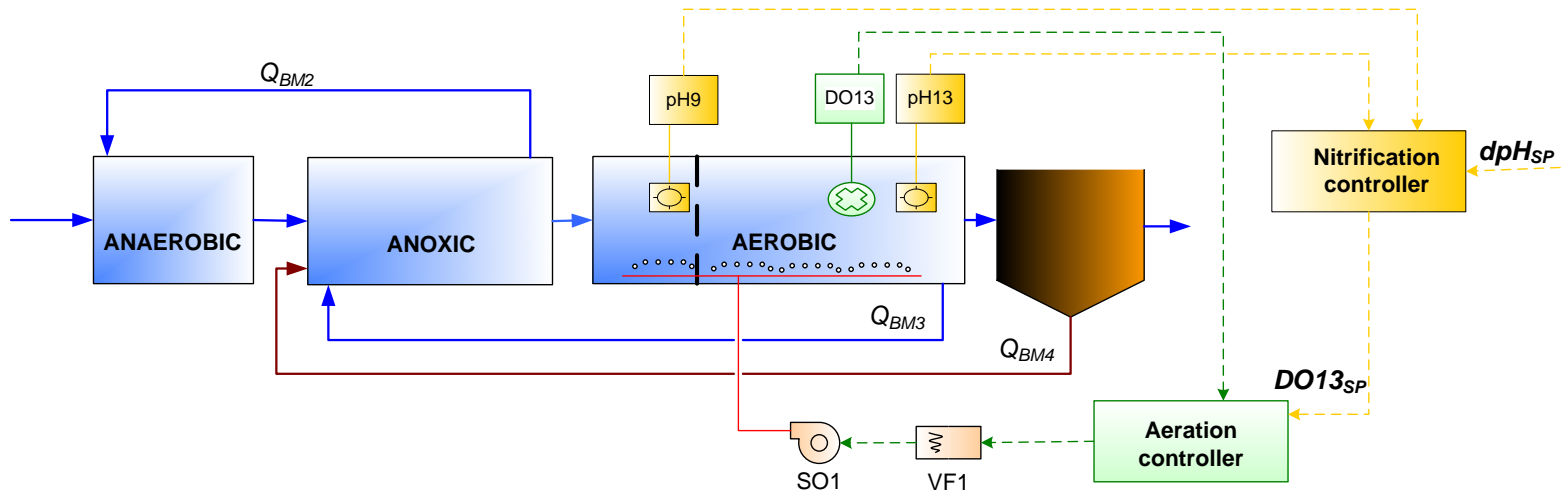

(a)

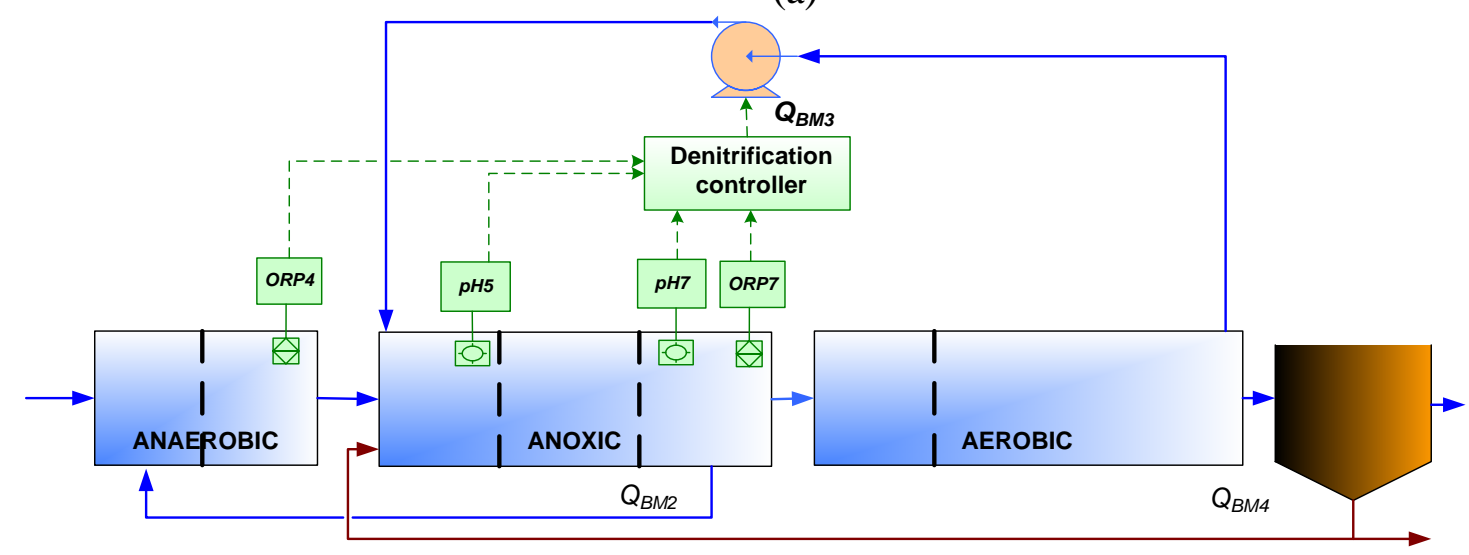

(b) 


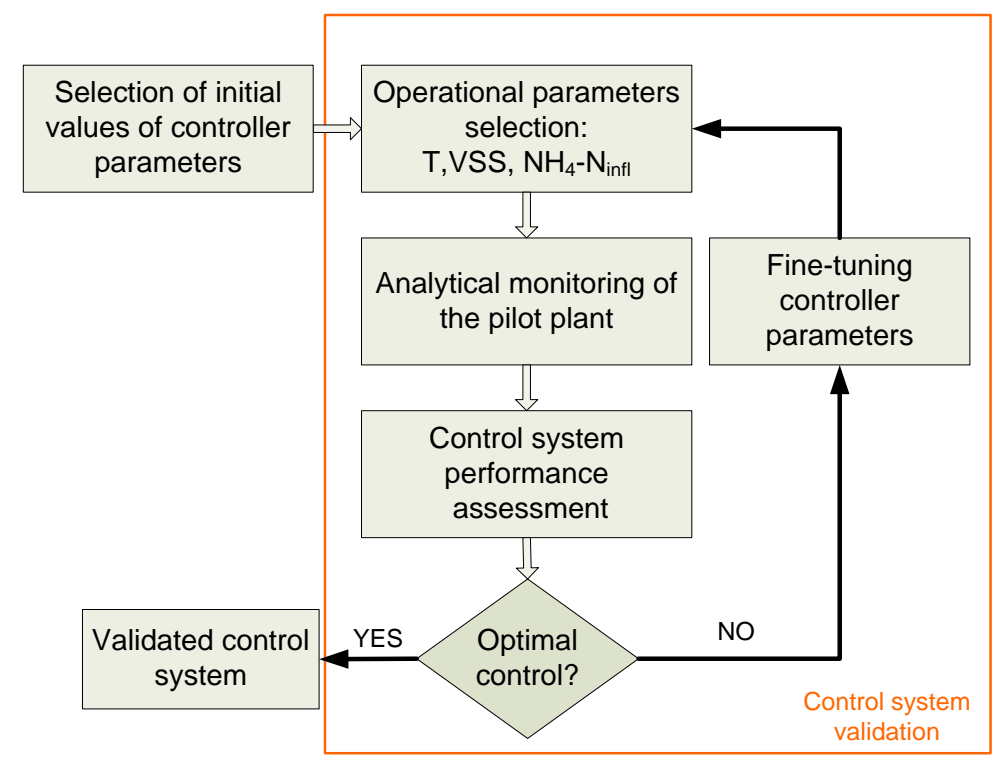




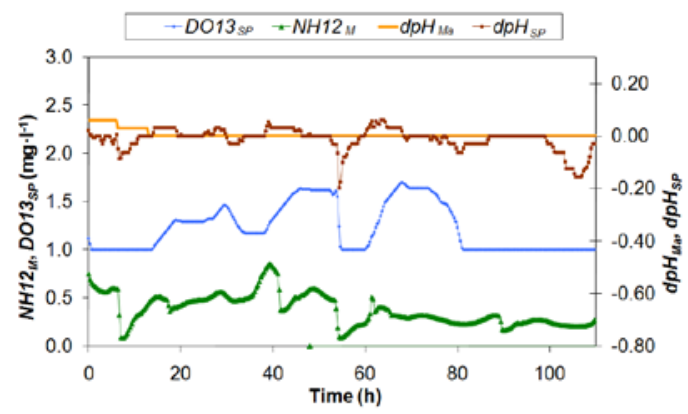

(a)

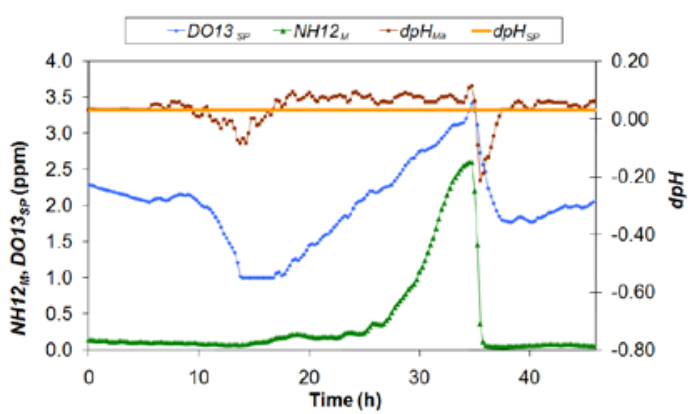

(c)

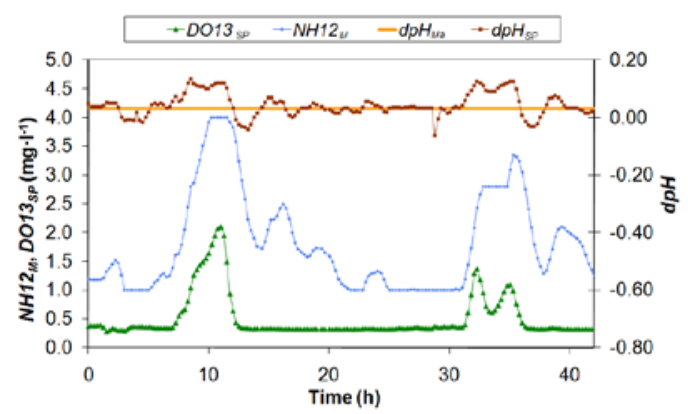

(e)

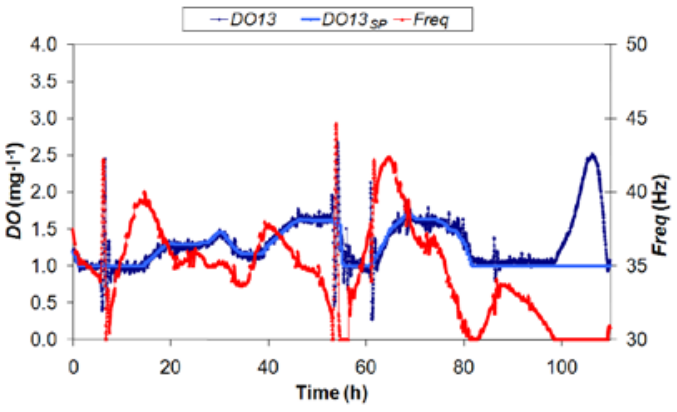

(b)

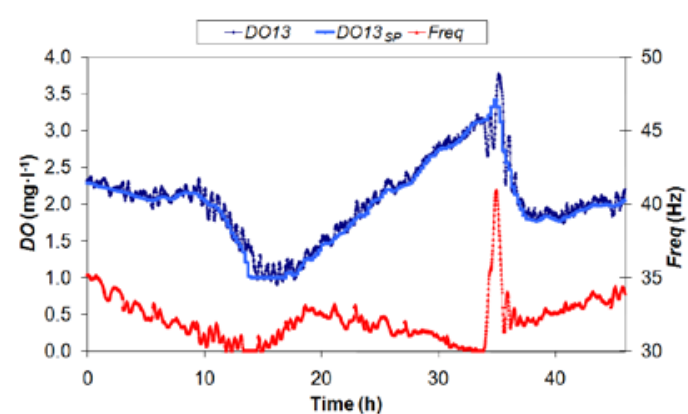

(d)

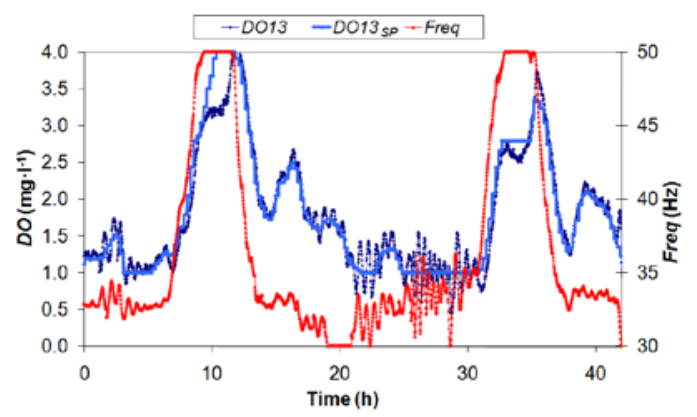

(f) 


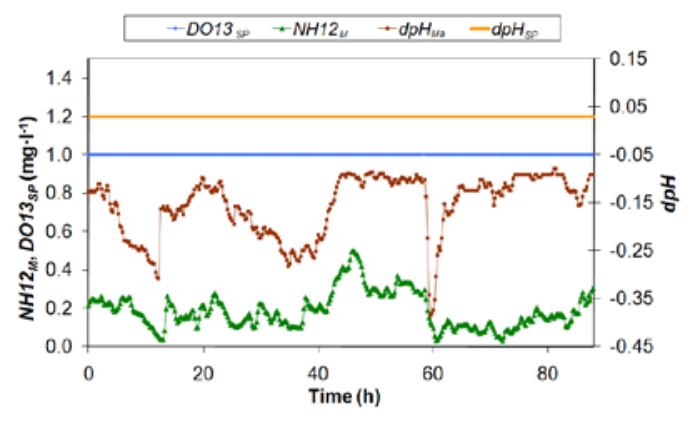

(a)

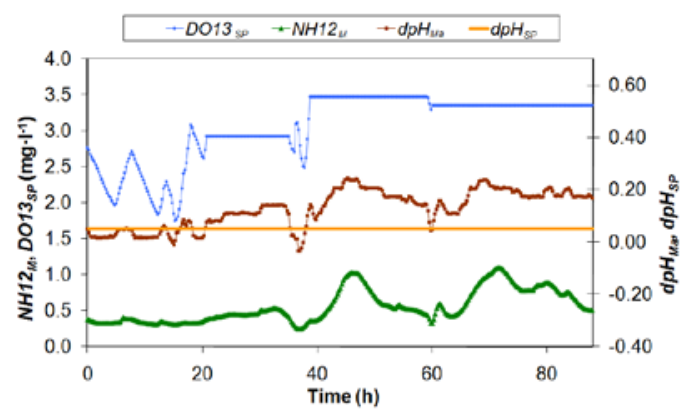

(c)

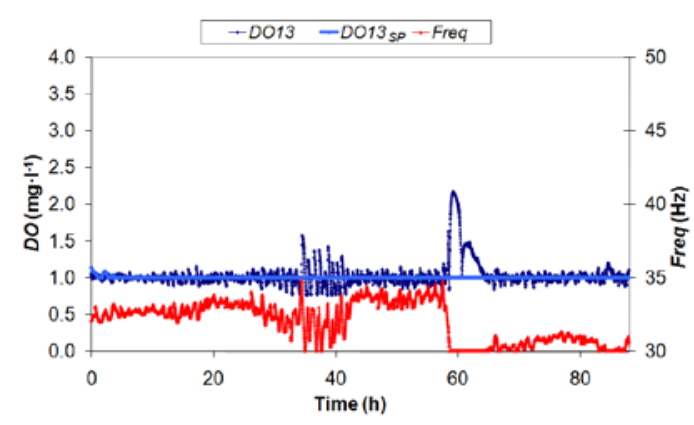

(b)

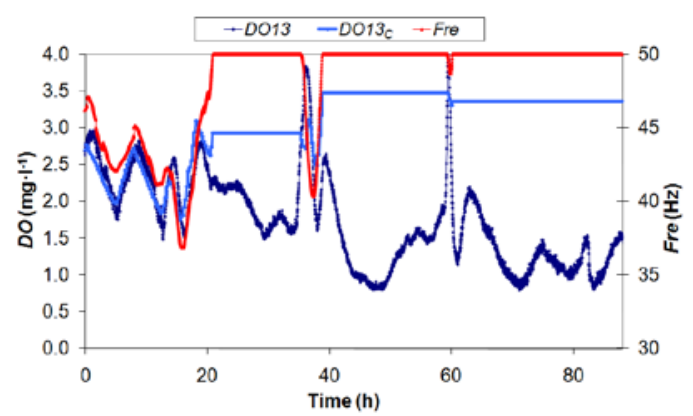

(d) 


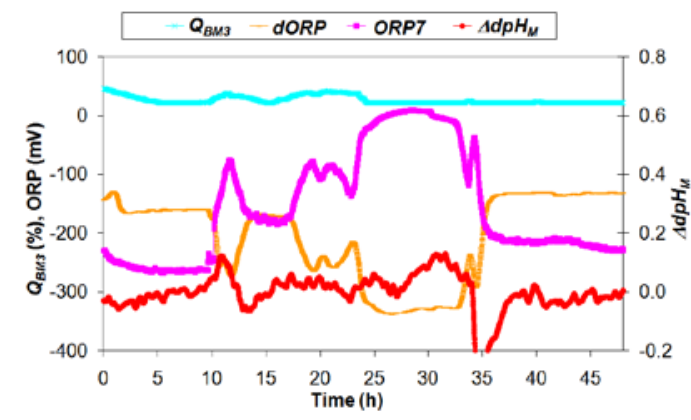

(a)

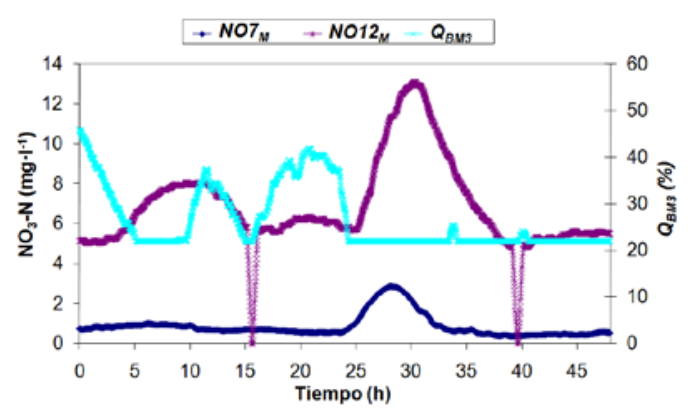

(b) 


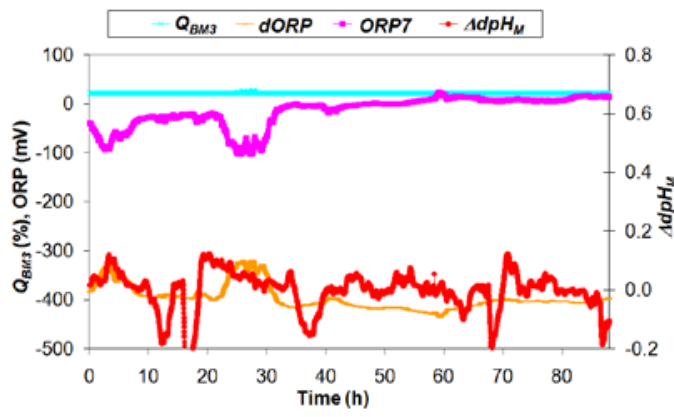

(a)

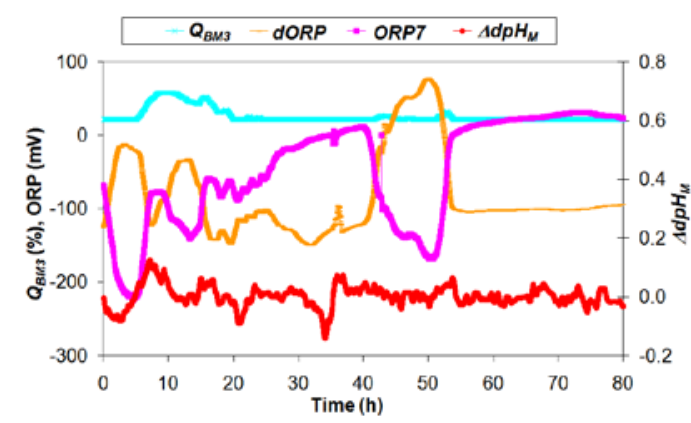

(c)

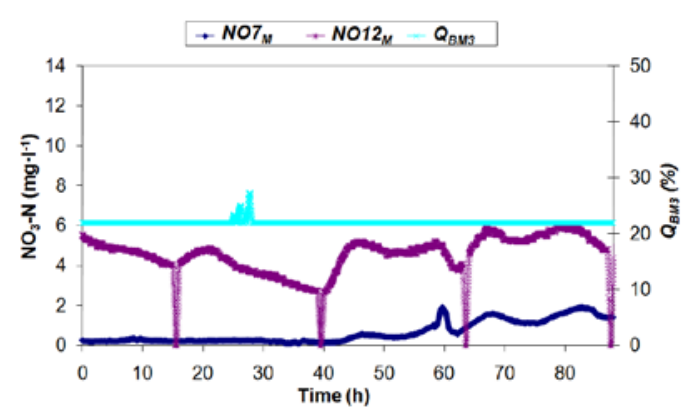

(b)

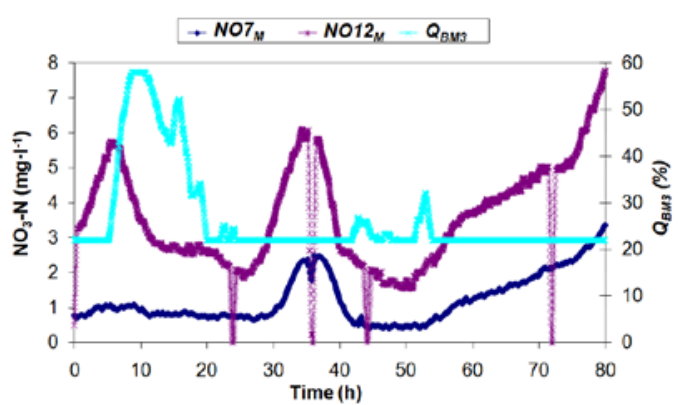

(d) 